\title{
Mating systems of diploid and allotetraploid populations of Tragopogon (Asteraceae). I. Natural populations
}

\author{
LINDA M. COOK* \& PAMELA S. SOLTIS \\ Department of Botany, PO Box 644238, Washington State University, Pullman, WA 99164-4238, U.S.A.
}

\begin{abstract}
Although polyploidy is a significant force in the diversification of plants, the evolutionary consequences of polyploidization are not thoroughly understood. One possible consequence of polyploidy predicted by most population genetic theories is that the newly synthesized polyploid will self-fertilize at a greater rate than its diploid progenitors. To test for increased selfing rates in a polyploid, the mating systems of the allotetraploid Tragopogon mirus and one of its diploid progenitors, T. dubius, were compared. Tragopogon mirus is a recently derived species that arose sometime in the last 80 years and thus provides an opportunity to probe how quickly a shift in outcrossing rates might occur. Based on analyses of variation in maternal plants and their progeny arrays, the two tetraploid populations surveyed have higher outcrossing rates than the two diploid populations. This result is the opposite of that predicted by population genetic theory. This discrepancy between theoretical and empirical results may result from bias in the genetic sample, traits in the natural histories of the taxa involved or a lack of sufficient time since the formation of the polyploid ( 80 years or 40-80 generations) for a shift towards increased selfing to have occurred. Alternatively, the partial dominance model of inbreeding depression typically applied to polyploids may not be appropriate; the overdominance model predicts outcrossing rates in diploids and their tetraploid derivatives that are consistent with those observed in T. dubius and T. mirus.
\end{abstract}

Keywords: allozymes, mating systems, polyploidy, Tragopogon.

\section{Introduction}

The evolution of new plant species through polyploidy represents a significant contribution to flowering plant diversity. Grant (1981) estimates that $47-52 \%$ of angiosperms are putatively of polyploid origin, and polyploidy among pteridophytes may be even higher, ranging from $43.5 \%$ for ferns (Vida, 1976) to $95 \%$ for all pteridophyte lineages (Grant, 1981) (although this value is open to question, given what is known about gene expression in pteridophytes with high chromosome numbers; reviewed in Soltis \& Soltis, 1989). Understanding the causes and consequences of polyploidy in plants is therefore pivotal to understanding the origin and diversification of nearly half of all species of angiosperms and pteridophytes. However, despite the evolutionary significance of polyploidy, its causes and consequences remain poorly understood. Unresolved issues include the extent of multiple origins of polyploid

*Correspondence. E-mail: lcook@mail.wsu.edu species, the modes and mechanisms by which polyploids arise and the genetic, genomic, ecological and evolutionary consequences of polyploidy.

\section{Theory and background}

One proposed evolutionary consequence of polyploidization in plants is a shift in the mating system of the polyploid, relative to its diploid progenitor(s). Several models predict that recently formed polyploids may be expected to show lower outcrossing rates than their diploid progenitors (e.g. Stebbins, 1971; Grant, 1981; Lande \& Schemske, 1985; Schemske \& Lande, 1985; Richards, 1986; Hedrick, 1987; Barrett \& Shore, 1989), and several lines of reasoning support this prediction.

Newly formed polyploids are typically reproductively isolated from their parental species in a single generation, making selfing necessary in order for the polyploid to survive and become established. Selection would then favour individuals with alleles that allow 
or promote selfing. It has frequently been argued that self-fertilization increases the likelihood that a newly arisen polyploid will persist, because backcrossing with either parental species results in sterile progeny (e.g. Stebbins, 1971; Grant, 1981). This situation is analogous to one in which a single member of a population disperses to colonize a new, isolated site. One of the selective advantages of such colonizers is the ability to self-fertilize successfully (Mackey, 1970). In such a case, selection would favour self-compatibility alleles, and their frequency would increase with each successive generation. In a newly formed polyploid, similar selective pressures would result in increased selfing rates relative to the diploid progenitor population.

The rate of homozygote increase following selfing in a population of an autopolyploid is predicted to be lower than the rate in either diploids (Busbice \& Wilsie, 1966; Dewey, 1966; Townsend \& Remmenga, 1968; Bennett, 1976) or allopolyploids (Dewey, 1966). Thus, a similar level of inbreeding in diploid and autopolyploid populations would result in lower levels of homozygosity in the polyploid population. Furthermore, the genetic load in populations of polyploids is less than in that of its diploid progenitors, resulting in lower inbreeding depression in the polyploid. It has been predicted that the often detrimental effects of selffertilization may be offset in polyploids by the buffering effect of duplicated loci (e.g. Stebbins, 1971; Richards, 1986; Barrett \& Shore, 1989); that is, polyploid populations carry a reduced genetic load. Hedrick's (1987) models suggest that polyploid plants should have a very small genetic load and therefore might be expected to show increased self-fertilization when compared with closely related diploids. However, self-fertilization increases the homozygosity of recessive deleterious alleles and therefore decreases the fitness of selfed progeny. The selective advantage of selfing may be offset by the detrimental effects of inbreeding depression. Lande \& Schemske (1985) predicted that diploid populations may be either highly selfing with low levels of inbreeding depression [because of the purging of deleterious alleles; Lande et al. (1994) showed that there is a threshold selfing rate below which this purging does not occur] or primarily outcrossing and exhibit high levels of inbreeding depression when selfed. Following the partial dominance model of inbreeding depression (Charlesworth \& Charlesworth, 1987; Husband \& Schemske, 1997), polyploids are expected to have lower levels of inbreeding depression than their diploid parents. In contrast, the overdominance model (Charlesworth \& Charlesworth, 1987) predicts higher levels of inbreeding depression in polyploids than in their diploid progeni- tors. Although distinguishing between these two genetic models of inbreeding depression is difficult, experimental evidence favours the partial dominance model (e.g. Wright et al., 1942; Willis, 1992; Husband \& Schemske, 1997; Sakai et al., 1997).

\section{The Tragopogon model}

To identify and interpret important aspects of polyploid formation and its consequences, the polyploid under investigation must have a clearly understood ancestry and must have originated recently enough to preclude the kind of divergence from its progenitor(s) that might obscure the relationships among the taxa. Two such polyploids are Tragopogon mirus and T. miscellus, tetraploid members of the North American Tragopogon complex. The three diploid members of the complex, $T$. dubius, T. porrifolius and T. pratensis, are native to and widespread throughout Europe and western Asia and were introduced into the Pacific Northwest region of North America early in the twentieth century.

The two tetraploid Tragopogons were discovered in 1949 (Ownbey, 1950) in the Palouse region of eastern Washington and adjacent Idaho, U.S.A., and their ancestries are now known with certainty (reviewed in Soltis et al., 1995). The progenitors of T. mirus are $T$. dubius and T. porrifolius; those of T. miscellus are $T$. dubius and $T$. pratensis. Because the diploid progenitors were not introduced into the Palouse before the early 1900s (Ownbey, 1950; Novak et al., 1991), the tetraploids could not have originated more than 75-80 years ago. The tetraploids have thus far been reported only in North America (Brown \& Schaak, 1972; Novak et al., 1991).

In the Palouse region, the five species are winter annuals or biennials (Cook et al., 1998) and inhabit disturbed sites in towns and cities; T. dubius has also invaded native vegetation in some locations (Novak et al., 1991). Plants of all five species are self-compatible and are visited by an array of generalist bees and flies (L. M. Cook, pers. obs.).

Tragopogon mirus and T. miscellus are two of only a few polyploids for which the parentage and time of origin are known with a high degree of certainty (see Soltis et al., 1995). Because the Tragopogons represent a recently formed polyploid complex, within which the progenitor and derivative relationships are clearly defined and understood (Ownbey, 1950; Soltis et al., 1995), they present a rare opportunity and provide a highly appropriate model for studying the evolutionary effects of polyploid speciation. We have used this species complex to test the predicted consequences of polyploidization on outcrossing rates in natural populations of these species. We hypothesized that populations of 
the tetraploid species T. mirus and T. miscellus would have lower outcrossing rates than populations of their diploid progenitors.

\section{Materials and methods}

\section{Populations sampled}

Based on a previous survey of allozymic diversity (Soltis et al., 1995), populations known to maintain polymorphisms at one or more loci were selected for sampling (Table 1). This survey had demonstrated at least low levels of polymorphism within populations of both tetraploid species and two of the three diploid progenitor species. No variability has been detected within populations of $T$. pratensis (Roose \& Gottlieb, 1976; Soltis et al., 1995). All of the polymorphic populations were chosen for the present study, but two populations had disappeared between 1991, when the original surveys were conducted, and 1993, when material for the present study was collected. The population of $T$. miscellus in Princeton, ID, U.S.A. and the small polymorphic population of $T$. mirus in Colfax, WA, U.S.A. were extinct by 1993. All of the remaining polymorphic populations were sampled.

\section{Seeds and leaves sampled}

Up to 50 maternal plants were sampled per population. If a population numbered fewer than 50 individuals, all of the plants that had set seed were sampled. From each maternal plant, leaf material and up to three seed heads were collected. Seed heads were collected only if the fruits were judged to be sufficiently mature for later germination of seeds. Samples were collected between 16 and 27 June 1993. Leaf material was stored at $-80^{\circ} \mathrm{C}$ in plastic bags, and seed heads were stored in envelopes in paper bags at room temperature while they ripened.

\section{Growth}

Collected seeds were allowed to ripen for at least 8 weeks. After ripening, seeds were planted in flats of 100 (10 seeds per head; up to 30 seeds per maternal plant) in the Washington State University Botany Department greenhouse. Seeds were planted between 26 August 1993 and 31 December 1993. Seedlings germinated in 4-7 days, and germination rates approached $100 \%$. Seedlings were allowed to grow for a minimum of 6 weeks; for sufficient expression of esterase (see below), it was necessary to allow seedlings to grow for 6 months.

\section{Enzyme electrophoresis}

Leaf material from each maternal plant (frozen) and all of the seedlings (fresh) was sampled for enzyme variation. Enzymes (Table 1) were analysed according to the general procedures of Soltis et al. (1983). The Tris- $\mathrm{HCl}$ grinding buffer with $12 \% \mathrm{PVP}(\mathrm{w} / \mathrm{v})$ was used for enzyme extraction, but modified to permit freezing of wicks at $-80^{\circ} \mathrm{C}$ by adding $10 \%$ DMSO. Extracts were adsorbed onto paper wicks and frozen. Wicks were thawed by adding a drop of a solution of $10 \mathrm{~mL}$ of water and $0.5 \mathrm{~mL}$ of 2-mercaptoethanol, and enzymes were electrophoresed through $12.5 \%$ starch gels. Esterase (EST) and leucine aminopeptidase (LAP) were resolved on gel and electrode buffer system 8 as modified by Haufler (1985), and 6-phosphogluconate dehydrogenase (6PGD) was resolved on system 9 (Soltis et al., 1983). Staining for enzymes was performed according to Soltis et al. (1995), with the following modifications: in the stain for LAP, the amount of L-leucine- $\beta$-naphthylamide was increased by $50 \%$ and, in the stain for EST, amounts of both $\alpha$-naphthyl acetate and $\beta$-naphthyl acetate were doubled.

Table 1 Tragopogon populations chosen for survey, the loci for which polymorphisms had been reported (Soltis et al., 1995) and whether or not these polymorphisms were recovered

\begin{tabular}{|c|c|c|c|c|}
\hline Species & Population & Polymorphic loci & Date sampled & $\begin{array}{l}\text { Polymorphisms } \\
\text { recovered? }\end{array}$ \\
\hline T. mirus & Old WSU Gate, Pullman, WA & Est-3 & $16 / 6 / 93$ & Yes \\
\hline T. mirus & Pufferbelly RR Depot, Pullman, WA & Est-3 & $17 / 6 / 93$ & Yes \\
\hline T. dubius & Sports Page Tavern, Pullman, WA & Est-3, Lap-2 & $18 / 6 / 93$ & Yes \\
\hline T. porrifolius & Palouse, WA & Est-1 & $22 / 6 / 93$ & No \\
\hline T. mirus & Colfax, WA & $6 P g d-2$ & Extinct & \\
\hline T. dubius & Troy, ID & Lap-1, 6 Pgd-2 & $24 / 6 / 93$ & Yes \\
\hline T. dubius & Juliaetta, ID & Est-3, Lap-1, 6Pgd-2 & 25/6/93 & No \\
\hline T. miscellus & Princeton, ID & Lap-2 & Extinct & \\
\hline T. miscellus & St. Maries, ID & $6 P g d-1$, Lap -2 & 27/6/93 & No \\
\hline T. miscellus & Spirit Lake, ID & $6 P g d-1$ & $27 / 6 / 93$ & No \\
\hline
\end{tabular}

(C) The Genetical Society of Great Britain, Heredity, 82, 237-244. 


\section{Data analysis}

Gels were scored and genotypes assigned to maternal parents and seedlings. For the four populations for which outcrossing rates were estimated, the number of maternal plants analysed per population ranged from 28 to 43 , the number of progeny per maternal plant ranged from six to 30 and the total number of progeny analysed per population ranged from 442 to 871 (Table 2). Outcrossing estimates, $t$, were obtained for each population, and standard errors were derived with 1000 bootstrap replicates, using the computer program MLT (Ritland, 1990). The distributions of $t$ derived from these bootstrap estimates were then compared to test for statistical differences in $t$ among populations. Statistically significant differences were detected by observing the distributions of the 1000 bootstrap estimates for each population. If the tails of these distributions overlapped at a level greater than $5 \%(2.5 \%$ at each end of the distribution), the samples were not considered statistically significantly different.

\section{Results}

No polymorphisms were detected in the samples of T. miscellus or T. porrifolius; the low-frequency polymorphisms reported previously (Soltis et al., 1995) were not detected in the samples for the current study. We therefore report results for two populations each of T. mirus and one of its diploid parents, T. dubius.

The outcrossing estimates $(t)$ varied among populations. Because each population of $T$. mirus was polymorphic at only one locus, the single-locus estimates from the populations of $T$. dubius will be used for comparison. These rates for the diploid populations did not differ significantly from their multilocus estimates (see Table 2). The population of T. dubius from Pullman $(t=0.068)$ approaches complete selfing, whereas the Troy population is much more highly outcrossing $(t=0.242)$. These outcrossing rates of the two populations of $T$. dubius are statistically different $(P<0.05)$.

The Pufferbelly and WSU populations of $T$. mirus had outcrossing rates of 0.381 and 0.456 , respectively (see Table 2); these values are not significantly different. The outcrossing rate for the Pufferbelly population does not differ significantly from that of the Troy population of $T$. dubius. The rates for the WSU population of T. mirus (0.456) and the Troy population of $T$. dubius (0.242) are nearly statistically different.

Wright's fixation index, $F$, was calculated for each population. All values were positive, ranging from 0.160 to 0.891 (Table 2), indicating a deficiency of heterozygotes relative to Hardy-Weinberg expectations.

\section{Discussion}

Wright's fixation index is an equilibrium statistic and gives an estimate of what has happened historically in the population (e.g. $F$-values near 0 suggest historically outcrossing populations). The outcrossing rate $t$ is an estimate of what has happened during the most recent generation and is less affected by factors such as selection and drift than is $F$. Therefore, $F$ - and $t$-values may seem to suggest different levels of outcrossing in a population, but they may not actually be contradictory. For example, the WSU population of T. mirus has both the highest outcrossing rate and the highest fixation index of all four populations. This may reflect a high level of fixation in the previous 5-10 generations, but the individuals in 1993 produced outcrossed seed. If individuals continue to outcross, then over time we would predict that the fixation index would decrease.

Table 2 Multilocus and single-locus estimates of $t$ and Wright's fixation index, $F$

\begin{tabular}{|c|c|c|c|c|c|}
\hline Species (ploidy) & Population & $\begin{array}{c}N \text { : Maternal } \\
\text { plants, progeny (range), } \\
\text { progeny (total) }\end{array}$ & $\begin{array}{l}\text { Multilocus } t \\
(95 \% \mathrm{CI})\end{array}$ & $\begin{array}{l}\text { Single-locus } \\
t(95 \% \mathrm{CI})\end{array}$ & $\begin{array}{l}\text { Wright's fixation } \\
\text { index } F(95 \% \mathrm{CI})\end{array}$ \\
\hline $\begin{array}{l}\text { T. dubius } \\
(2 n)\end{array}$ & Pullman, WA & $35,8-29,607$ & $\begin{array}{c}0.063 \\
(0.004-0.120)\end{array}$ & $\begin{array}{c}0.068 \\
(0.004-0.134)\end{array}$ & $\begin{array}{c}0.160 \\
(-0.168-0.431)\end{array}$ \\
\hline $\begin{array}{l}\text { T. dubius } \\
(2 n)\end{array}$ & Troy, ID & $43,6-26,442$ & $\begin{array}{c}0.245 \\
(0.144-0.362)\end{array}$ & $\begin{array}{c}0.242 \\
(0.136-0.363)\end{array}$ & $\begin{array}{c}0.352 \\
(0.109-0.546)\end{array}$ \\
\hline $\begin{array}{l}\text { T. mirus } \\
(4 n)\end{array}$ & $\begin{array}{l}\text { Pullman, WA, } \\
\text { Pufferbelly RR Depot }\end{array}$ & $43,8-30,871$ & & $\begin{array}{c}0.381 \\
(0.271-0.461)\end{array}$ & $\begin{array}{c}0.531 \\
(0.232-0.776)\end{array}$ \\
\hline $\begin{array}{l}\text { T. mirus } \\
(4 n)\end{array}$ & $\begin{array}{l}\text { Pullman, WA, } \\
\text { Old WSU Gate }\end{array}$ & $28,7-29,465$ & & $\begin{array}{c}0.456 \\
(0.360-0.610)\end{array}$ & $\begin{array}{c}0.891 \\
(0.716-1.00)\end{array}$ \\
\hline
\end{tabular}

Sample sizes for each population of Tragopogon are given as the number of maternal plants analysed, the range of numbers of progeny analysed per maternal plant and the total number of progeny analysed. Confidence intervals shown in parentheses are based on 1000 bootstrap replicates. 
Given that the tetraploid populations are no more than 75-80 years old and may even have gone extinct and been re-established within that time (see Soltis et al., 1995), they may not have had sufficient time to reach equilibrium.

Several lines of reasoning predict that polyploids may be expected to show lower outcrossing rates than their diploid progenitors (see above). Alleles that promote selfing in the polyploid may be favoured, leading to polyploid populations that have high selfing rates. Relative to diploids, polyploids are consistently predicted to approach homozygosity more slowly (MacKey, 1970; Bennett, 1976). This slower approach to homozygosity should result in lower inbreeding depression under the partial dominance model (Charlesworth \& Charlesworth, 1987). Under these conditions, the mating system of a polyploid population could evolve towards increased selfing. However, this shift could take time, making it possible that older polyploids might show greater selfing than relatively new polyploids.

The estimates of $t$ in this study do not support expectations for diploid-tetraploid pairs based on population genetic theory. The prediction that this newly formed tetraploid species would exhibit lower levels of outcrossing than its diploid progenitor was not supported. Several explanations can be offered to reconcile the discrepancy between theoretical and empirical results. First, the estimates of outcrossing reported here may be biased. The low levels of allozymic polymorphism within and among the Palouse Tragopogon populations (Soltis et al., 1995) may lead to underestimates of outcrossing because many crosses between identical genotypes will go undetected. However, this source of bias would apply equally to both tetraploid and diploid populations, and outcrossing estimates would be low for both. Furthermore, the more polymorphic loci that are available for estimating $t$, the better the estimate should be. For example, if there existed a heterozygote advantage at one locus and the outcrossing estimate were based upon that locus, $t$ would be inflated owing to the excess of heterozygotes created by their advantage. Alternatively, single-locus estimates may underestimate outcrossing rates because a crossing event between two homozygous individuals would go undetected. The addition of more loci to the analysis increases the chances that such an outcrossing event, undetected at one locus, might be evidenced at another locus. In this study, the diploid populations were each polymorphic at two loci, so the multilocus estimates obtained for the diploid populations should be more accurate than the singlelocus estimates for the tetraploids. However, the outcrossing estimates for the diploid populations are lower than for the tetraploid populations. Hence, even if the estimates reported here are underestimates of the real outcrossing rates, the tetraploid populations appear to be more highly outcrossing than their diploid progenitor, in direct contrast to predictions by most population genetic models.

Accepting the outcrossing rates estimated here as real, we offer several explanations for the observed deviation from predictions. Some possible explanations are based on the natural history and pollination biology of these plants in their non-native ranges on the Palouse. Because the diploid Tragopogon species were introduced from Europe, any native pollinators with which they may have evolved are absent. If there are any specialized relationships between a given species of Tragopogon and specific pollinators in the native ranges, they are unlikely to be repeated in the Palouse area. In fact, the Tragopogons on the Palouse are visited by a diverse array of generalist bees and flies (L. M. Cook, pers. obs.). The Tragopogon species may compete for these pollinators and, if so, the tetraploid may have advantages over the diploid, leading to more pollinator visits and, hence, higher outcrossing rates in the tetraploids. The tetraploid $T$. mirus is typically more robust, with larger flowering heads than T. dubius; this increased size may make it more obvious and attractive to pollinators. In addition, the inflorescences of the two species differ in colour: the heads of $T$. dubius are entirely yellow, whereas the heads of $T$. mirus are purple with a yellow eye. If any of the generalist visitors are cued by blues or purples in flower colour, then the tetraploids might receive more visits, if pollinators preferentially visit purple heads and less frequently move among the yellow heads of $T$. dubius. Furthermore, although all Tragopogons are heliotropic, the diploid and tetraploid species respond differently to sunlight. The flowering heads of both $T$. dubius and T. mirus open in early morning and close by midday. The capitulae of $T$. dubius begin closing between 10.00 hours and noon, depending on the heat of the day, and by 13.00 hours (perhaps later on overcast days) the capitulae of $T$. dubius are virtually all closed. The flowering heads of $T$. mirus, in contrast, may stay wide open until 11.00 hours or 12.00 hours, and even on hot days may still remain open until 14.00 hours (L. M. Cook, pers. obs.). Whether this latter time actually increases the opportunity for pollination is unknown because, by this time, the majority of the pollinators are no longer active. Peak visitation time is between 08.00 hours and noon, depending on temperature (L. M. Cook, pers. obs.), and there may well be an ample window during the second half of that time frame when the tetraploid capitulae are more open and receptive to pollinator visits than are those of the diploids. 
Outcrossing rates can vary widely among populations within a species (e.g. Brown et al., 1989). The two populations of $T$. dubius for which outcrossing estimates were obtained here may not be (and probably are not) the specific populations that gave rise to the two T. mirus populations in the study (Cook et al., 1998). If the tetraploid populations arose from diploid populations with higher outcrossing rates than the diploids sampled here, then the higher outcrossing rates observed in these tetraploid populations may simply result from inheritance of alleles for higher outcrossing from the diploid populations that originally gave rise to these tetraploids.

Another possible explanation for the apparent increased outcrossing rates in T. mirus relative to T. dubius is that the tetraploid may have inherited a trait or traits from its other parent, T. porrifolius, which increase its outcrossing rate. Although T. porrifolius has no known differences from $T$. dubius for traits such as capitulum size or pollen-ovule ratio, we know that $T$. porrifolius is self-compatible; bagged heads set viable seed in the field and in the greenhouse (L. M. Cook, unpubl. data). No data are available regarding outcrossing rates in $T$. porrifolius, because no allozyme polymorphisms were detected in this study; however, if $T$. porrifolius is highly outcrossing and this mating system is genetically based, then we would expect to see elevated outcrossing rates in its allotetraploid derivative. Following similar reasoning, we can infer that, because the tetraploid species arose from hybridization, the parental individuals were outcrossing, at least to some extent, and passed the trait(s) responsible for outcrossing on to their tetraploid derivative.

Finally, it may simply be that we are viewing the tetraploid species too early in its evolution for us to observe increased selfing in the tetraploid. For selfing to increase, time is needed for selection to favour selfing, once a mutation has arisen to permit higher selfing in the tetraploids. Given the recent origin of T. mirus (Ownbey, 1950), insufficient time may have passed to permit the evolution of increased selfing rates.

Few studies have tested the hypothesis that polyploids may exhibit higher selfing rates than their diploid progenitors, and even fewer have dealt with newly or recently derived polyploids (but see Marshall \& Abbott, 1982; Ashton \& Abbott, 1992; Abbott \& Forbes, 1993; Ingram \& Noltie, 1995). Soltis \& Soltis (1990) and Masuyama \& Watano (1990) presented evidence that polyploid pteridophytes have higher selfing rates than their diploid progenitors. The polyploid fern Ceratopteris thalictroides shows high levels of gametophytic selfing and low levels of genetic load, both of which are attributed at least partly to the fern's polyploidy (Watano \& Masuyama, 1991). The autotetraploid cactus Pachycereus pringlei has populations with both female and hermaphroditic individuals. Whereas the females were expected and observed to exhibit complete outcrossing, the hermaphroditic plants exhibited high levels of selfing and little inbreeding depression (Murawski et al., 1994). Diploid and tetraploid populations of Epilobium angustifolium showed no differences in outcrossing rates, but the tetraploids had lower levels of inbreeding depression than the diploids (Husband \& Schemske, 1997).

Studies of diploid and polyploid populations of Scandinavian Draba species present contrasting results (Brochmann, 1993). The diploid species, D. fladzinensis, $D$. nivalis and $D$. subcapitata, were almost completely selfing, but the polyploid species, D. oxycarpa $(8 x)$ and D. corymbosa (16x), exhibited levels of outcrossing that, although low, differed statistically from zero. Brochmann (1993) hypothesized that allopolyploidy in Arctic species of Draba serves as an escape from the genetic depauperation caused by uniparental inbreeding at the diploid level. In this historical context, these polyploids could not possibly have been any more inbreeding than the progenitors, which are virtually completely inbred; the formation of the allopolyploids must have resulted from rare outcrossing events. These are not newly derived polyploids, and there may have been sufficient time for selection to have favoured even the slight advantages conferred by the occasional outcrossing in the polyploids.

The allohexaploid Senecio cambrensis exhibits a high selfing rate, equivalent to that of one of its progenitors but very unlike that of the other of its progenitors, which is self-incompatible (Marshall \& Abbott, 1982; Abbott \& Forbes, 1993; Ingram \& Noltie, 1995). In these cases at least, the results appear to contradict most population genetic theory, although for reasons that may differ from those proposed for the Tragopogon case.

\section{Conclusions}

Outcrossing rates in natural populations of the tetraploid T. mirus were higher than those in populations of one of its diploid parents, T. dubius. This result was not expected, based on most population genetic models for polyploid mating systems, which predict lower outcrossing rates in polyploids than in their diploid progenitors. The results may be explained, at least in part, by possible differences in the pollination biology of the two species, by a genetic component contributed by the second (unsampled) diploid parental species or by the fact that there has not been enough time for selection to modify the mating system. The outcrossing rates estimated here may also be influenced by inbreeding depression. It is not known whether inbreeding depression varies between diploid and 
tetraploid Tragopogon populations but, following the overdominance model rather than the partial dominance model cited above (Charlesworth \& Charlesworth, 1987), the tetraploids would have higher inbreeding depression than the diploids, so there could be selection to maintain higher outcrossing rates. Estimates of inbreeding depression in these populations could help to explain the differences in outcrossing rates observed here. Whatever may be responsible for the higher outcrossing rates in tetraploid Tragopogon populations, it may be important to confirm that these results are not an artifact of the low allozymic diversity observed among all species of Tragopogon in the Palouse region (Soltis et al., 1995). The outcrossing estimates obtained from wild populations using isozyme genotypes probably represent an underestimate of actual outcrossing. It would be useful to estimate outcrossing rates in artificial populations, constructed to maximize the chances of detecting outcrossing events. Such data could then be compared with the estimates obtained in this study to see whether the tetraploids continue to show higher outcrossing rates than the diploids. If the apparent mating system shift towards greater outcrossing in this neopolyploid species is real, these data may illustrate how quickly evolutionary shifts may occur.

\section{Acknowledgements}

This research was supported by grants to L.M.C. from Sigma Xi, the American Society of Plant Taxonomists and the Hardman Foundation, and by NSF grant no. DEB-9624643 to P.S.S. and L.M.C. We thank Doug Soltis, Steve Brunsfeld, Steve Novak and an anonymous reviewer for constructive comments on the manuscript; John Thompson and Martin Morgan for helpful discussions; and Brad Cook and Beth Halleck for help and support in collecting seeds and leaf material.

\section{References}

ABBOTT, R. J. AND FORBES, D. G. 1993. Outcrossing rate and selfincompatibility in the colonizing species Senecio squalidus. Heredity, 71, 155-159.

AShton, P. A. AND Aввотt, R. J. 1992. Multiple origins and genetic diversity in the newly arisen allopolyploid species, Senecio cambrensis Rosser (Compositae). Heredity, 68, 2532.

BARRETT, S. C. H. AND SHORE, J. S. 1989. Isozyme variation in colonizing plants. In: Soltis, D. E. and Soltis, P. S. (eds) Isozymes in Plant Biology, pp. 106-126. Dioscorides Press, Portland, OR.

BENNETT, J. H. 1976. Expectations for inbreeding depression on self-fertilization of tetraploids. Biometrics, 32, 449-452.
BROCHMANN, C. 1993. Reproductive strategies of diploid and polyploid populations of arctic Draba (Brassicaceae). Pl. Syst. Evol., 185, 55-83.

Brown, A. H. D., BURdon, J. J. AND JARosz, A. M. 1989. Isozyme variation in colonizing plants. In: Soltis, D. E. and Soltis, P. S. (eds) Isozymes in Plant Biology, pp. 73-86. Dioscorides Press, Portland, OR.

BROWN, R. K. AND SCHAAK, C. G. 1972. Two new species of Tragopogon for Arizona. Madrono, 21, 304.

BUSBICE, T. H. AND WILSIE, C. P. 1966. Inbreeding depression and heterosis in autotetraploids with application to Medicago sativa L. Euphytica, 15, 55-83.

CHARLESWORTH, D. AND CHARLESWORTH, B. 1987. Inbreeding depression and its evolutionary consequences. Ann. Rev. Ecol. Syst., 18, 237-268.

COOK, L. M., SOLTIS, P. S., BRUNSFELD, S. J. AND SOLTIS, D. S. 1998. Multiple independent formations of Tragopogon tetraploids (Asteraceae): Evidence from RAPD markers. Mol. Ecol. 7, 1293-1302.

DEWEY, D. R. 1966. Inbreeding depression in diploid, tetraploid, and hexaploid crested wheatgrass. Crop Sci., 6, 144-147.

GRANT, v. 1981. Plant Speciation, 2nd edn. Columbia University Press, New York.

HAUfLER, C. H. 1985. Enzyme variability and modes of evolution in Bommeria (Pteridaceae). Syst. Bot., 10, 92-104.

HEDRICK, P. W. 1987. Genetic load and the mating system in homosporous ferns. Evolution, 41, 1282-1289.

HUSBAND, B. C. AND SCHEMSKE, D. W. 1997. The effect of inbreeding in diploid and tetraploid populations of Epilobium angustifolium (Onagraceae): implications for the genetic basis of inbreeding depression. Evolution, 51, 737746.

INGRAM, R. AND NOLTIE, H. J. 1995. Senecio cambrensis Rosser. J. Ecol., 83, 537-546.

LANDE, R. AND SCHEMSKE, D. W. 1985. The evolution of selffertilization and inbreeding depression in plants. I. Genetic models. Evolution, 39, 24-40.

LANDE, R., SCHEMSKe, D. W. AND SCHUltz, S. T. 1994. High inbreeding depression, selective interference among loci, and the threshold selfing rate for purging recessive lethal mutations. Evolution, 48, 965-978.

MACKEY, J. 1970. Significance of mating systems for chromosomes and gametes in polyploids. Hereditas, 66, 165-176.

MARShAll, D. F. AND ABBOTT, R. J. 1982. Polymorphism for outcrossing frequency at the ray floret locus in Senecio vulgaris L. I. Evidence. Heredity, 48, 227-235.

MASUYAMA, S. AND WATANO, Y. 1990. Trends for inbreeding in polyploid pteridophytes. Pl. Sp. Biol., 5, 13-17.

MURAWSKI, D. A., FLEMING, T. H., RITLAND, K. AND HAMRICK, J. L. 1994. Mating system of Pachycereus pringlei: an autotetraploid cactus. Heredity, 72, 86-94.

NOVAK, S. J., SOlTIS, D. E. AND SOlTIS, P. S. 1991. Ownbey's Tragopogons: forty years later. Am. J. Bot., 78, 1586-1600.

OWNBEY, M. 1950. Natural hybridization and amphiploidy in the genus Tragopogon. Am. J. Bot., 37, 487-499.

Richards, A. J. 1986. Plant Breeding Systems. George Allen and Unwin, London.

RITLAND, K. 1990. A series of FORTRAN computer programs for estimating plant mating systems. J. Hered., 81, 235-237.

(C) The Genetical Society of Great Britain, Heredity, 82, 237-244. 
RoOSE, M. L. AND GOTTLIEB, L. D. 1976. Genetic and biochemical consequences of polyploidy in Tragopogon. Evolution, 30, 818-830.

SAKAI, A. K., WEller, S. G., CHEN, M.-L., CHOU, S.-Y. AND TASANONT, C. 1997. Evolution of gynodioecy and maintenance of females: the role of inbreeding depression, outcrossing rates, and resource allocation in Schiedea adamantis (Caryophyllaceae). Evolution, 51, 724-736.

SCHEMSKE, D. W. AND LANDE, R. 1985. The evolution of selffertilization and inbreeding depression in plants. II. Empirical observations. Evolution, 39, 41-52.

SOLTIS, D. E. AND SOLTIS, P. S. 1989. Polyploidy, breeding systems, and genetic differentiation in homosporous pteridophytes. In: Soltis, D. E. and Soltis, P. S. (eds) Isozymes in Plant Biology, pp. 241-258. Dioscorides Press, Portland, OR.

SOLTIS, P. S. AND SOLTIS, D. E. 1990. Evolution of inbreeding and outcrossing in ferns and fern-allies. Pl. Sp. Biol., 5, 1-11.

SOlTIS, D. E., HAUfLER, C. H., GASTONY, G. J. AND DARROW, D. C. 1983. Starch gel electrophoresis of ferns: a compilation of grinding buffers, gel and electrode buffers, and staining schedules. Am. Fern J., 73, 9-27.
SOLTIS, P. S., PLUNKETT, G. M., NOVAK, S. J. AND SOLTIS, D. E. 1995. Genetic variation in Tragopogon species: additional origins of the allotetraploids T. mirus and T. miscellus (Compositae). Am. J. Bot., 82, 1329-1341.

StebBins, G. L. 1971. Chromosomal Evolution in Higher Plants. Edward Arnold, London.

TOWNSEND, C. E. AND REMMENGA, E. E. 1968. Inbreeding in tetraploid alsike clover, Trifolium hybridum L. Crop Sci., 8, 213-217.

VIDA, G. 1976. The role of polyploidy in evolution. In: Novak, V. J. A. and Pacltova, I. (eds) Evolutionary Biology, pp. 267304. Czechoslovak Academy of Sciences, Prague.

WATANO, Y. AND MASUYAMA, s. 1991. Inbreeding in natural populations of the annual polyploid fern Ceratopteris thalictroides (Parkeriaceae). Syst. Bot., 16, 705-714.

WILLIS, J. H. 1992. Genetic analysis of inbreeding depression caused by chlorophyll-deficient lethals in Mimulus guttatus. Heredity, 69, 562-572.

WRIGHT, S., DOBZHANSKY, T. AND HOVANITZ, w. 1942. Genetics of natural populations. VII. The allelism of lethals in the third chromosome of Drosophila pseudoobscura. Genetics, 27, 363-394. 